It is only possible at this stage to guess at the origin of these beautiful designs, but I hope in the near future to make further investigations which may throw more light on the problem.

(Whether the crystals observed by Dr. Schneider are a form of anchor ice or "drowned " sublimation crystals presents an interesting problem. A recent letter from Dr. Schneider describing further investigations made as soon as the glaciers became snow-free in 1948 casts doubt on the latter alternative, namely that the crystals formed by sublimation in winter and became submerged by spring thaw. It would be interesting to hear from anyene else who has
found these crystals in glacier holes. Ed.)

$M S$. received 24 November 1947

\title{
STAGNANT GLACIER IN BRITISH COLUMBIA
}

During Mr. F. S. Smythe's expedition in 1947 to the Lloyd George Mountains, British Columbia, the particularly interesting discovery was made of a large dying glacier. It lay in a deep canyonlike valley below the highest peaks of the group (see Fig. 3, p. 177). It was entirely blanketed in its own moraine and on its surface was a liberal growth of plants and small conifers, some of which reached $4.5 \mathrm{~m}$. in height. The glacier is $3.5 \mathrm{~km}$. long with a maximum width of some $400 \mathrm{~m}$. Its upper limit lies at about $1800 \mathrm{~m}$. and its snout at about $1350 \mathrm{~m}$.

Neither the small cliff-glacier at its snout, nor the avalanche snow from the precipitous rock walls enclosing it, appear to provide this glacier with any appreciable nourishment. The dead black ice could be seen in occasional exposures in sink-holes and at the glacier borders. The ice appeared to extend as far as the original terminal moraine. The melt water issuing from the latter was of moderate amount and scarcely turbid.

Since there was no clear evidence of recent glaciation beyond the terminal moraine, it seems probable that this glacier may be an example of re-establishment subsequent to the "climatic optimum," as has been claimed for others in the Cordilleran ranges.

As far as is known, this glacier is the only one in the Canadian Rockies proper in which the whole body of ice lies dead and stagnating beneath its mantle of moraine. It would seem to offer an example of what may well have occurred extensively at the close of the Glacial Epoch in regions of high relief possessing canyon-like or fjord valleys.

N. E. ODELL

\section{THE PRESERVATION OF ICE SPECIMENS IN REF R I GERA TOR S}

ON p. $21_{5}$ of this issue will be found an abstract from a paper by Dr. A. D. Howard describing the storage of samples of ice and their transference from the Antarctic to Washington. As one of the "European glaciologists" mentioned therein I would like to offer a word of caution. We certainly found that vaseline preserved ice specimens for the short time between collection and examination-usually a matter of a day or two. But M. de Quervain* has more recently made some experiments which show that under certain conditions the prevention of air contact is not sufficient. In the case of very delicate specimens such as snow flakes, immersion in paraffin oil at $-5^{\circ} \mathrm{C}$. did not prevent modifications in structure due to the surface migration of molecules. On the other hand at $-10^{\circ} \mathrm{C}$. no alteration could be detected even after some months.

G. Seligman

* Experientia (Basel), Bd. 1, Heft 7, 1945, p. 8. 